\title{
Biochemical Comparison of Commercial Selenium Yeast Preparations
}

\author{
Sheena Fagan • Rebecca Owens • Patrick Ward • \\ Cathal Connolly $\cdot$ Sean Doyle $\cdot$ Richard Murphy
}

Received: 17 October 2014 / Accepted: 18 January 2015 / Published online: 18 February 2015

(C) Springer Science+Business Media New York 2015

\begin{abstract}
The trace mineral selenium (Se) is an essential element for human and animal nutrition. The addition of Se to the diet through dietary supplements or fortified food/feed is increasingly common owing to the often sub-optimal content of standard diets of many countries. Se supplements commercially available include the inorganic mineral salts such as sodium selenite or selenate, and organic forms such as Se-enriched yeast. Today, Se yeast is produced by several manufacturers and has become the most widely used source of Se for human supplementation and is also widely employed in animal nutrition where approval in all species has been granted by regulatory bodies such as the European Food Safety Authority (EFSA). Characterisation and comparison of Se-enriched yeast products has traditionally been made by quantifying total selenomethionine (SeMet) content. A disadvantage of this approach, however, is that it does not consider the effects of Se deposition on subsequent digestive availability. In this study, an assessment was made of the water-soluble extracts of commercially available Se-enriched yeast samples for free, peptide-bound and total water-soluble SeMet. Using LCMS/MS, a total of 62 Se-containing proteins were identified across four Se yeast products, displaying quantitative/ qualitative changes in abundance relative to the certified reference material, SELM-1 ( $P$ value $<0.05$; fold change $\geq 2$ ). Overall, the study indicates that significant differences exist between Se yeast products in terms of SeMet content, Se-
\end{abstract}

Electronic supplementary material The online version of this article (doi:10.1007/s12011-015-0242-6) contains supplementary material, which is available to authorized users.

S. Fagan $(\varangle) \cdot$ P. Ward $\cdot$ C. Connolly $\cdot$ R. Murphy

Alltech Biotechnology Centre, Dunboyne, County Meath, Ireland

e-mail: sfagan@alltech.com

R. Owens $\cdot$ S. Doyle

Department of Biology, Maynooth University, Maynooth, County

Kildare, Ireland containing protein abundance and associated metabolic pathways.

Keywords Selenium · Yeast · Selenomethionine · Speciation $\cdot$ Supplementation $\cdot$ Proteomics $\cdot$ LC-MS/MS

\section{Introduction}

Selenium (Se) is an essential micronutrient for humans and animals playing important roles in antioxidant function, thyroid hormone metabolism, reproduction and immune responses [1]. Supplementation of farm animal diets with Se is stimulated by the beneficial effect of this element on animal health and, consequently, by the improved quality of foodstuffs of animal origin [2]. Furthermore, several studies on animal models, cell lines and human intervention trials have demonstrated cancer protective effects of selenium [3].

The compounds available for use as Se supplements include the inorganic forms, sodium selenite and sodium selenate, and the organic forms, L-selenomethionine (SeMet) and Se-enriched yeast [4]. Although the metabolism of both organic and inorganic Se forms shows certain similarities, not all of these forms are metabolised alike, and humans have been found to absorb and retain Se better from SeMet than from the inorganic Se salts [5-7]. In a number of studies in humans and animals, in particular, those on Se-deficient diets, the bioavailability of Se from Se-enriched yeasts and the bioavailability of SeMet has been shown to be approximately 1.5 - to 2-fold higher than that of inorganic forms of Se $[8,9]$. Consequently, the biological actions of Se depend not only on the amount but also on the form of the Se source [10] and on the digestibility and accessibility of selenoamino acids from the protein-rich yeast matrix [11]. 
Proteins containing Se in the form of SeMet residues are not formally classified as selenoproteins but rather called selenium-containing proteins [12]. Therefore, in the case of organic Se products such as Se yeast, biological efficacy is more dependent on the digestibility and accessibility of Secontaining proteins and peptides present in commercial preparations. An assessment of the composition of Se yeast products in the marketplace indicated that significant differences exist between the products [13]; however, speciation studies traditionally focused on the determination of low molecular mass selenocompounds [12].

In recent years, the methodology used in classical proteomics has been gradually incorporated into analytical speciation studies. The application of both elemental and organic mass spectrometry methods, usually preceded by liquid chromatography, has become commonplace in studies on selenoproteins and selenium-containing proteins [14]. Proteomic techniques such as liquid chromatography-tandem mass spectrometry (LC-MS/MS) enable the study of the vast nature of proteins and the correlation with their underlying biological processes. This allows the identification of their abundance changes, levels of production, post-translation modification, amino acid substitutions and polymorphisms to be determined. For this reason, physiological and nutritional alterations can play a pivotal role in altering the proteome of an organism facilitating the differentiation and discrimination of Se yeast products [15].

In this study, an assessment was made of the water-soluble extracts of Se-enriched yeast samples for free, peptide-bound and total water-soluble SeMet. LC-MS/MS was used to identify and quantify individual proteins present in the soluble extracts. Protein identities were validated using UniProt, and Gene Ontology classification was performed to define the potential biological role of the identified proteins and their relevance to animal health [16]. Characterisation of Se yeast in this way provides a unique fingerprint of origin and accounts for fate of Se during the production process, which is paramount importance for regulatory and safety agencies [17]. The Se-enriched yeast certified reference material (SELM-1) was used for the calibration of instruments and evaluation of methods for the determination of SeMet, Met and total Se in yeast. This appears to be the first reported study using gel-free and label-free quantification for the proteomic assessment of water-soluble extracts of Se-enriched yeast products.

\section{Materials and Methods}

\section{Selenised Yeast Samples}

Samples from three non-consecutive production batches of four commercially available Se yeast products were used in all biochemical and proteomic analyses. The certified reference material, SELM-1, was the test material for the inductively coupled plasma mass spectrometry (ICP-MS) validation study and control for proteomic analyses [18].

Extraction of Free, Bound and Total Selenomethionine from Yeast Samples

Protease XIV and Trizma Base were obtained from Sigma. Methanol (HPLC grade) and trifluoroacetic acid (TFA) were supplied by Sigma. All chemicals used in this work were of analytical-reagent grade or higher unless otherwise specified.

\section{Sample Extraction of Total SeMet}

Approximately $0.04 \mathrm{~g}$ of Se yeast sample was accurately weighed into $1.5 \mathrm{~mL}$ microcentrifuge tubes. Protease enzyme solution (13.33 mg Protease XIV in $0.5 \mathrm{~mL}$ of Tris buffer $\mathrm{pH}$ 7.5) was added and vortex mixed for 2 min. Samples were ultrasonicated for $25 \mathrm{~s}$ at $80 \%$ amplitude and the probe washed with $250 \mu \mathrm{L}$ enzyme solution into the $1.5 \mathrm{~mL}$ tube. Some ice and water were placed into the microwave carousel, and the microcentrifuge tubes were placed into the carousel holder (up to 14 tubes per run). The extraction program was operated for $15 \mathrm{~min}$ at a power output of $30 \mathrm{~W}$. Extracted samples were centrifuged at 14,000 rpm for $3 \mathrm{~min}$. Supernatants were then transferred in to $15 \mathrm{~mL}$ centrifuge tubes. Pellets were washed with water $(0.9 \mathrm{~mL})$ and vortex-mixed until completely in solution. Samples were centrifuged at 14 , $000 \mathrm{rpm}$ for $6 \mathrm{~min}$ and supernatants added to the $15 \mathrm{~mL}$ centrifuge tubes. This step was repeated three times. Volumes were adjusted to $15 \mathrm{~mL}$ using water and mixed well before removing an aliquot $(2 \mathrm{~mL})$ for filtration $(0.25 \mu \mathrm{m})$ and dilution before analysis.

\section{Sample Extraction of Water-Soluble Free SeMet}

Approximately $0.5 \mathrm{~g}$ of Se yeast sample was accurately weighed into $50 \mathrm{~mL}$ sterilin tubes. HPLC-grade water $(5$ $\mathrm{mL}$ ) was added. Samples were placed on a shaker for $15 \mathrm{~min}$ at $300 \mathrm{rpm}$. Samples were then centrifuged at $8500 \mathrm{rpm}$ for $10 \mathrm{~min}$. Aliquots $(2 \mathrm{~mL})$ of supernatants were filtered $(0.25 \mu \mathrm{m})$ and diluted before analysis.

\section{Sample Extraction of Water-Soluble-Bound SeMet}

Water extracts $(500 \mu \mathrm{L})$ were added to $13.33 \mathrm{mg}$ of protease. Samples were ultrasonicated for $25 \mathrm{~s}$ at $80 \%$ amplitude and the probe washed with $250 \mu \mathrm{L}$ enzyme solution $(6.667 \mathrm{mg}$ Protease XIV/250 $\mu \mathrm{L}$ ) into $1.5 \mathrm{~mL}$ tubes. Some ice and water were placed into the microwave carousel, and the microcentrifuge tubes were placed into the carousel holder (up to 14 tubes per run). The extraction program was operated for $15 \mathrm{~min}$ at a power output of $30 \mathrm{~W}$. The extracted samples 
were centrifuged at 14,000 rpm for $3 \mathrm{~min}$. Supernatants were then transferred into $15 \mathrm{~mL}$ centrifuge tubes. Volumes were adjusted to $15 \mathrm{~mL}$ using water and mixed well before removing an aliquot $(2 \mathrm{~mL})$ for filtration $(0.25 \mu \mathrm{m})$ and dilution before analysis.

\section{Instrumentation and Calibration}

Separations were performed on an Agilent Zorbax RX-C8 4.6 $\times 250 \mathrm{~mm} 5 \mu \mathrm{m}$ column using an Agilent Technologies 1260 infinity series LC system connected to an Agilent Technologies $7700 \times$ series ICP-MS. The mobile phase was water/methanol/TFA (97.9:2.0:0.1) at a flow rate of $1 \mathrm{~mL} / \mathrm{min}$, and the column temperature was set at $30^{\circ} \mathrm{C}$.

A Heinemann 130W ultrasonic-homogeniser (HTU SONI 130, USA) equipped with a $3 \mathrm{~mm}$ double step titanium probe was used for sample preparation. A CEM Discover microwave equipped with an Explorer SP-D Plus 24/48 autosampler was used for sample extraction. An ELGA Purelab Flex S7 HPLC water system was used to produce $>18 \mathrm{M} \Omega \mathrm{cm}$ water, and samples were filtered using Chromafil Xtra RC-20/25. The HPLC mobile phase was filtered with Whatman Glass Microfibre Filters.

SeMet standard powder was obtained from Sigma ( $>98 \%$ by TLC). This was used to prepare a $100 \mathrm{mg} / \mathrm{L}$ stock solution in $0.1 \mathrm{M} \mathrm{HCl}$. Aliquots $(0.1 \mathrm{~mL})$ of this solution were frozen and used fresh each day.

The instrument was calibrated over the range of 50 to $250 \mathrm{ppb}$ SeMet (20.15 to $100.75 \mathrm{ppb}$ Se as SeMet) as described previously [19].

\section{Sample Analysis for ICP-MS}

Aliquots $(2 \mathrm{~mL})$ of the sample extracts were filtered into $2 \mathrm{~mL}$ microcentrifuge tubes. Further dilutions were made using HPLC-grade water and transferred to $2 \mathrm{~mL}$ HPLC vials for analysis. Each sample was analysed in triplicate using an injection volume of $45 \mu \mathrm{L}$ and monitored for isotopes ${ }^{76} \mathrm{Se},{ }^{77} \mathrm{Se}$ and ${ }^{78} \mathrm{Se}$.

\section{Sample Preparation for LC-MS}

Protein concentration of water extracts (1/10 dilution) was quantified using the Bradford assay, and all solutions were adjusted to the same concentration. Approximately $150 \mu \mathrm{g}$ of protein was precipitated from each sample using TCA/ acetone precipitation. Samples were solubilised in $6 \mathrm{M}$ urea/2 $\mathrm{M}$ thiourea solution, and all samples were again adjusted to the same concentration as necessary. Samples were reduced and alkylated, with DTT and IAA, respectively, followed by overnight trypsin digestion in the presence of ProteaseMax (Promega) mass spectrometry-compatible detergent [20]. Digestion activity was quenched by acidification, and samples were desalted using $\mathrm{C}_{18}$ ZipTips (Millipore) prior to analysis. Desalted samples were dried to completion and resuspended in loading solvent $(2 \%(v / v)$ acetonitrile, $0.05 \%$ $(v / v)$ TFA) immediately prior to LC-MS/MS analysis.

\section{LC-MS/MS Analysis}

The analysis of the water extracts was performed using a reverse phase column $(15 \mathrm{~cm} \times 75 \mu \mathrm{m}$ inner diameter $)$ packed with $3 \mu \mathrm{m} \mathrm{C}_{18}$ particles (EASY-Spray; Thermo Scientific). All samples were separated on a $2 \mathrm{~h}$ acetonitrile gradient (5$35 \%$ ) in $0.1 \%$ formic acid at a flow rate of $300 \mathrm{~mL} / \mathrm{min}$, using the UltiMate 3000 Nano LC system from Dionex. The LC was coupled to a Q-Exactive mass spectrometer (Thermo Fisher Scientific) with up to the top 15 most abundant isotope patterns selected for fragmentation (MS/MS) (Top 15 method). The Q-Exactive was operated in data-dependent mode with survey scans (MS) acquired at a resolution of 70,000 at $\mathrm{m} / \mathrm{z}$ 400 , while MS/MS scans were acquired at a resolution of 17 , 500 .

\section{Data Analysis}

The MS data were analysed using MaxQuant version 1.3.0.5 [21] with protein identification achieved through comparison against the Saccharomyces cerevisiae reference strain S288C database (www.yeastgenome.org). Carbamidomethylation of cysteines was set as a fixed modification, while oxidation of methionines, acetylation of $\mathrm{N}$-terminals and selenium-sulphur substitution were set as variable modifications. The maximum peptide/protein false discovery rates (FDR) were set to $1 \%$ based on comparison to a reverse database. The label-free quantitative (LFQ) algorithm was used to generate normalised spectral intensities and infer relative protein abundance. Proteins that matched to a contaminants database or the reverse database were removed, and proteins were only retained in final analysis if detected in at least two samples from at least one product. Quantitative analysis was performed using a $t$ test to compare pairs of samples, and proteins with significant change in abundance ( $P$ value $<0.05$; fold change $\geq 2$ ) were included in the quantitative results. Qualitative analysis was also performed, to detect proteins that were found in at least two batches of a particular product, but undetectable in the comparison product.

\section{Results and Discussion}

Determination of Total, Free and Bound Selenomethionine

There is a common misconception that the level of SeMet is an appropriate indication for the bioavailability of selenised yeast preparations [22]. In actuality, selenium bioavailability 
depends on the digestion of Se-containing yeast, the absorption of Se from the intestinal tract and finally the transport and biotransformation of Se into biologically active forms [11]. Therefore, estimation of adequate levels of Se in the diet requires information not only of the total amount of Se but also of the bio-accessible species in the sample $[6,23,24]$. Seenriched yeast has been extensively studied and fractionated $[12,25]$ with SeMet reported as the major selenoamino acid in water-soluble yeast extracts, replacing Met by simple competition. Se yeast products consist of dried and inactivated preparations of S. cerevisiae; the final product is a light to dark brown, free-flowing powder readily dispersible in water and organic solvents [26-28]. Aqueous extraction allows the recovery of $15-25 \%$ of Se [12] present predominately as protein-bound SeMet [29, 30]; therefore, an enzymatically assisted extraction method is typically used to determine total SeMet content [11]. Essentially, larger SeMet-containing proteins and peptides are broken down into free amino acids and short-chain peptides liberating the selenoamino acid for detection [19]. Figure 1 shows the difference between the five yeast products used in this study in terms of free, peptide-bound and total water-soluble selenomethionine $(P<0.01)$.

There was significant variation noted in the product specific inter-batch levels of free, peptide-bound and total watersoluble SeMet $(P<0.01)$ except for yeast product 2 , which did not display such inconsistency $(P=0.1$ and 0.012 , respectively). Product 1 had the highest variability in peptide-bound water-soluble SeMet across the three batches assessed. This may be due to the age of the sample or alterations that may have been made to the fermentation process between batches [31]. Another factor which may contribute to variation in final concentration of SeMet between batches and/or products is the number of washes applied post-production. Typically, the residual sodium selenite used during production is removed by washing the yeast cream prior to drying [32]. It has been proposed that some SeMet in yeast may not be incorporated chemically into Se-containing proteins but physically associated with cell wall constituents $[3,23]$. As commercial Se yeast preparations consist of dried and inactivated fragments of $S$. cerevisiae, it is reasonable to assume that some leaching may occur post-production and prior to drying [12].

Product 4 consistently contained the most free SeMet in each batch, whereas product 3 contained the least. It is important to make this distinction between total SeMet and free SeMet, as only the free form of this selenoamino acid is available for non-specific incorporation into proteins in place of methionine, leading to Se-containing proteins, representing a biological pool of $\mathrm{Se}$ [7]. Unless selenium-containing proteins and peptides are digested to liberate SeMet as a free amino acid, then regardless of total Se and/or total SeMet content, the Se source must undergo a metabolic transformation to selenide prior to its assimilation $[24,33]$. Hinojosa-Reyes et al. $[11,34]$ reported that $89 \%$ of total Se was extracted after in vitro gastrointestinal (GI) digestion of a selenised yeast standard, but surprisingly, only $41 \%$ was quantified in the form of free SeMet. Therefore, although this free selenoamino acid appears to be the most abundant Se species in GI digests, half of the total SeMet content in the extracts still seems to be associated with Se-containing peptides after in vitro GI digestion [35]. A similar study by Encinar et al. [12] examined the composition of three commercial preparations of Se-enriched yeast in terms of Se deposition within individual yeast fractions. Each product was extracted with water followed by a variety of enzymic digestions intended to liberate selenocompounds associated with various polysaccharide and protein portions. Their study on the recovery of the different classes of Se species demonstrated significant differences between Se yeast samples from different sources.
Fig. 1 Selenomethionine partitioning in commercially available yeast products. a,b,c,d,e Average values that lack a common superscript letter differ in significance $(P \leq 0.05)(n=9)$

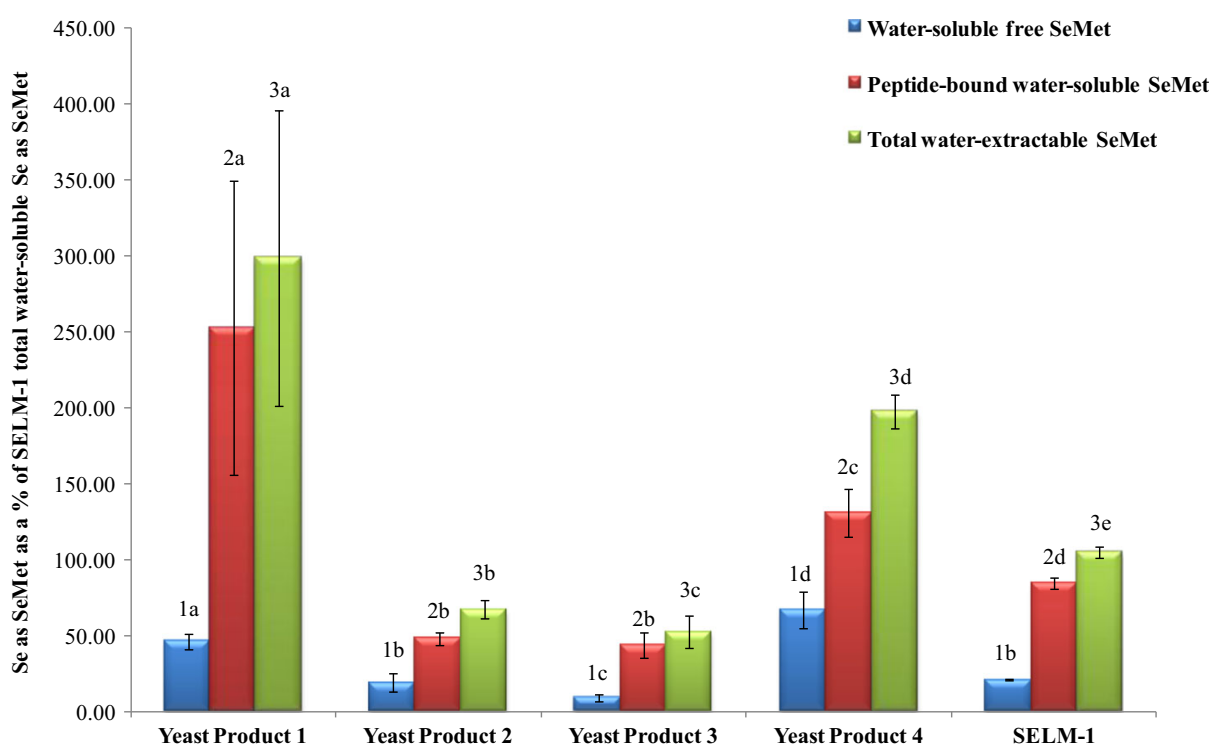


Similarly, based on the values reported in the present study, it is apparent that the profiles of water-extractable SeMet differ markedly, indicating that all sources of 'selenium yeast' are not alike. It is clear that the compartmentalisation of Se within yeast matrix is different between preparations and is straindependent [36] and, consequently, it is reasonable to expect that these preparations will also differ in parameters such as shelf-life, bioavailability and, indeed, toxicology [37]. How these data related to actual bioavailability of selenium within the animal can only be speculative [13]; therefore, simulated in vitro GI digestion studies will be required to establish a complete overview of bioavailable intake [11, 38].

Although enzymatic hydrolysis is a powerful tool for distinguishing between fractions, it is clear that there are inherent difficulties with enzymatic release of SeMet which may lead to lower recoveries [39]. For instance, SeMet may not be fully liberated from the protein, peptide or other cellular components with which it is associated, and it may be solubilised in forms which get lost during the derivatisation or chromatography steps or may interact non-specifically with sample components [40]. It must also be noted that Se-containing proteins are labile and prone to degradation after being extracted [41] leading to an underestimation of the Se content. However, inclusion of the certified reference material, SELM1 , in intercomparison Se speciation and quantitation studies, validates the reported values [18].

A top-down proteomic approach incorporating liquid chromatography with tandem mass spectrometry can also alleviate issues with extraction, enzymatic digestion and incomplete derivatisation [42]. In addition, a deeper insight into the identity of the proteins can be obtained by tryptic digestion and investigation of the Se-containing peptides formed [43].

\section{Determination of Inter-batch and Inter-product Protein Content Variation Between Se Yeast Products}

In addition to the determination of the level of organic Se (as SeMet), a series of analytical methods are routinely used to ensure the quality and origin of the finished Se yeast product. These include assessment of strain purity using biochemical and genetic identification techniques, measurement of moisture control and quantification of toxic impurities such as lead, arsenic and cadmium [39]. In recent years, proteomic techniques such as LC-MS are increasingly used to measure changes in protein abundance across the samples that are being compared [44]. Relative quantifications allow the accurate determination of protein ratios in samples that are genetically or physiologically similar or diverse [45]. To determine the variation in protein content between batches and products, label-free mass-spectrometry-based proteomic analysis, scatter correlation plots and hierarchical clustering were performed. As previously mentioned, a proteomic approach such as LC-MS/MS can circumvent potential issues with extraction, enzymatic digestion and incomplete derivatisation associated with Se speciation studies [40].

Scatter plots of protein intensities revealed high correlation (low variation) between batches of the same products, indicating good reproducibility of batches and technical preparation of samples (Fig. 2a-e). Pearson correlation coefficients (where 1 = identical) were calculated between all pairs of batches within a product group, and these indicated that the lowest variability was observed within the SELM-1 product group (Pearson coefficient 0.983-0.985) which is to be expected as there is only one production batch of this certified reference material (CRM) available commercially. As the SELM-1 water extract was prepared in triplicate from the same batch, the low variation in this sample is reflective of the high reproducibility of the sample analysis, i.e. protein extraction, digestion and LC-MS analysis. All batches clustered to their individual product groups except for one. Yeast product 2 sample C clustered closer to SELM-1 than the other products, which may have resulted from an overall high similarity between yeast product 2 and SELM-1 (Fig. 3: Pearson coefficient 0.948). Overall, these results indicate high sample reproducibility, which is of paramount importance for label-free quantitative (LFQ) proteomic analysis [46].

For determination of inter-product variation, a comparison of all five products was also carried out using scatter plot analysis and hierarchical clustering. The normalised intensities of all proteins were generated by MaxQuant analysis, these values were $\log _{2}(\mathrm{x})$ transformed and the mean value was calculated for each product group. Yeast products 2-4 and SELM-1 all demonstrated a high level of correlation (Fig. 3: Pearson coefficient $>0.84$ for all pairs) which makes these products suitable for analysis within an LFQ proteomic experiment [47]. However, LFQ proteomic analysis revealed that yeast product 1 clustered independently of all other products based on protein composition (Fig. 3; Pearson coefficient $<0.56$ for all pairs). Hierarchical clustering again confirmed this poor correlation, with yeast product 1 grouping away from the other Se-enriched products (Fig. 4a) thus highlighting the need for multiple statistical analyses. The poor correlation between yeast product 1 and all other products is in agreement with the inconsistencies noted for SeMet partitioning in this present study and previous studies addressing the composition of Se yeast products from different sources [12]. This extent of variation makes yeast product 1 unsuitable for comparison in an LFQ proteomic experiment, which is normally predicated on the basis that the majority of proteins remain unchanged in a comparison set [48]. With yeast product 1 excluded from the analyses, a total of 786 proteins were identified across the remaining four products, of which 374 proteins displayed quantitative/qualitative changes in abundance relative to SELM-1 ( $P$ value $<0.05$; fold change $\geq 2$ ) (Supplementary Table 1). 
Fig. 2 Multi-scatter correlation plots of four selenium-enriched products and SELM-1 reference material. Scatter plots demonstrating the variation within product batches for yeast products 1-4 (a-d), SELM-1 (e); batches/replicates tested are indicated $(A-C)$. Axis values represent the $\log _{2}(\mathrm{x})$ value of the normalised intensity of each protein. Values in blue are Pearson correlation coefficients and indicate the level of variation between sample groups (colour figure online)
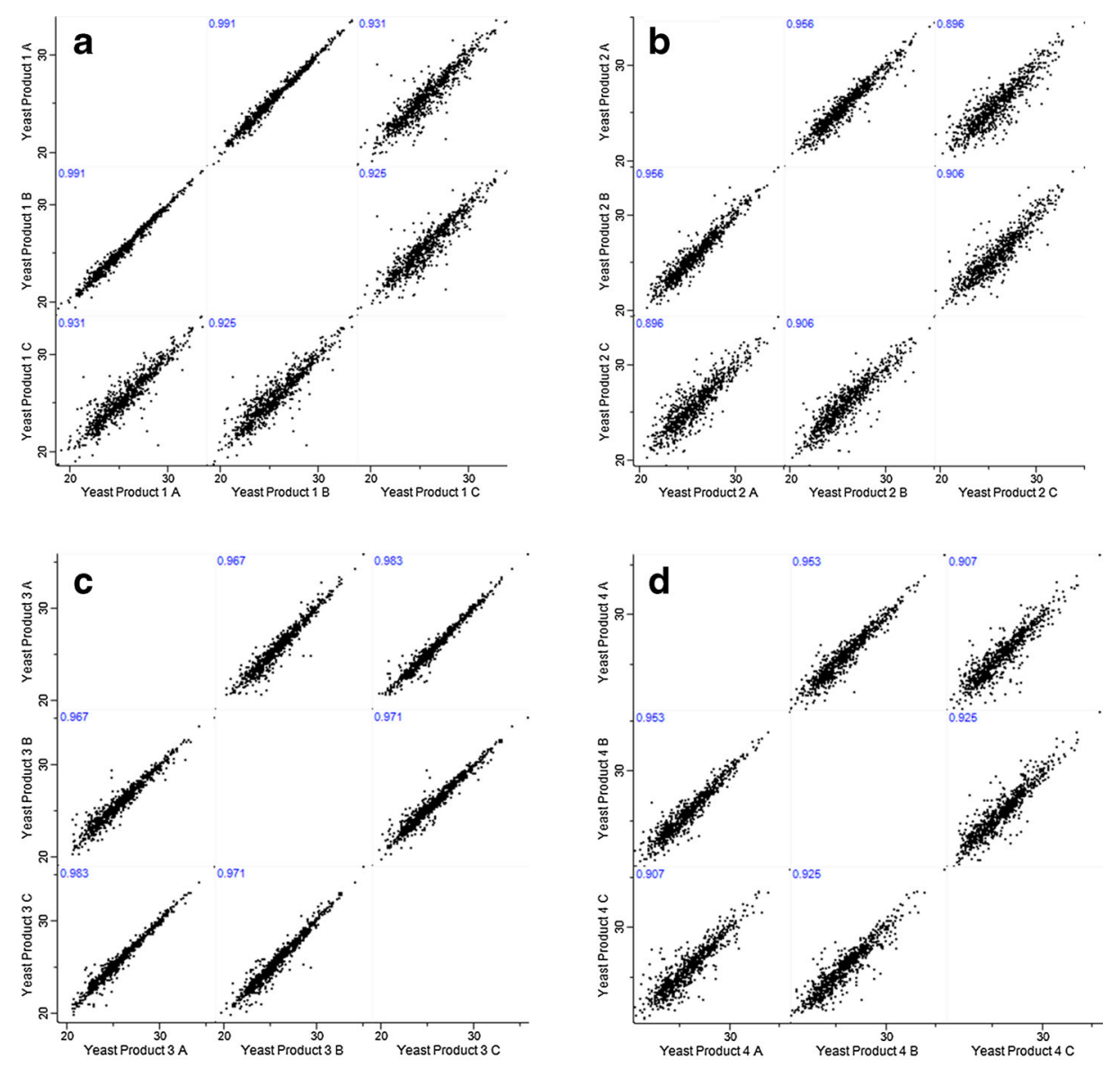

Product 2 demonstrated the least disparity from SELM-1, and these products were also seen to cluster together on the heat maps (Fig. 4) again indicating high strain or product similarity. Although proteomic analysis revealed overall batch reproducibility of individual products, it also successfully differentiated outliers and highlighted potential inconsistencies in production processes, which is in agreement with the previously discussed SeMet standard deviation. In addition, although SeMet partitioning indicated similar concentrations for products 2 and 3 in terms of peptide-bound water-soluble SeMet, hierarchical clustering revealed that product 3 is in fact the most dissimilar to product 2 and, indeed, all other products. A deeper insight into protein abundances and identities (Fig. 4) can be achieved by further interrogation of the data for Se-containing proteins. 
Fig. 3 Multi-scatter correlation plots of four selenium-enriched products and SELM-1 reference material. Scatter plots demonstrating the variation within product batches for yeast products $1-4$ and SELM-1. Axis values represent the $\log _{2}(\mathrm{x})$ value of the normalised intensity of each protein. Variation between the products, based on the mean log-transformed intensity for each protein, is shown. Values in blue are Pearson correlation coefficients and indicate the level of variation between sample groups. Yeast product 1 (red box) demonstrated poor correlation to all of the other products analysed (Pearson coefficients $<0.56$ ) (colour figure online)

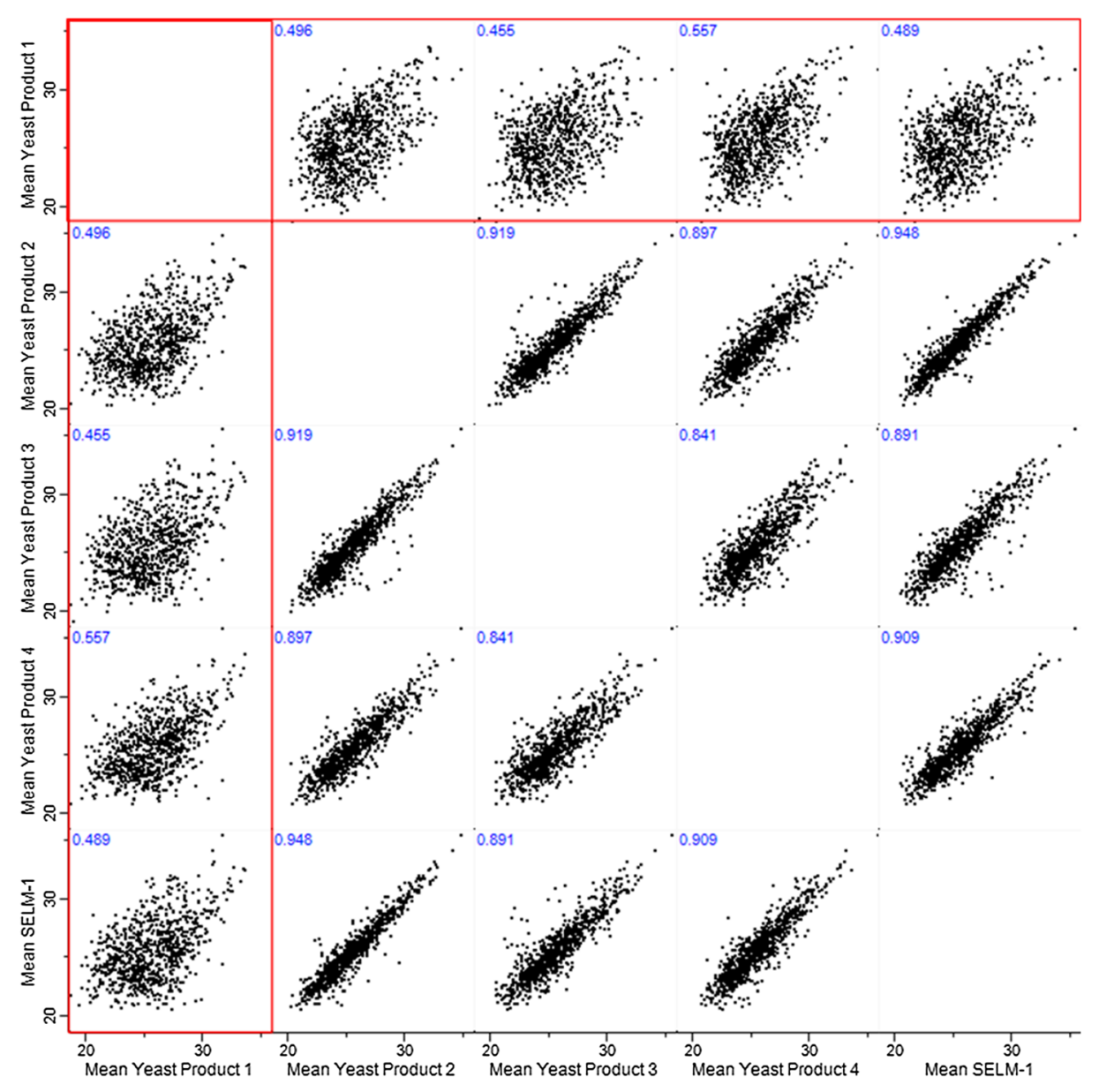

Analysis for Se-Containing Proteins

Interrogation of the data generated from the four products (excluding Yeast product 1) revealed the identification of a number of selenopeptides ( $n=186$ unique peptides), corresponding to 116 unique protein groups. These modifications were associated with 172 SeMet replacements and 14 selenocysteines (SeCys). Proteins identified with SeMet/ SeCys containing peptides were extracted from the quantitative results (Supplementary Table 1), and this subset is presented in Table 1 (62 proteins in total). A description of each protein is provided along with its respective fold-change in abundance (fold change $\geq 2$ ) relative to SELM-1.

The Panel on Additives and Products or Substances used in Animal Feed (FEEDAP Panel) has regularly expressed its view that all SeMet sources would result in similar selenium deposition (EFSA 2011a, b, 2012); this view was later extended to the hydroxy-analogue of SeMet (HMSeBA) (EFSA, 2013). Since L-SeMet is the predominant selenocompound incorporated into proteins of Se yeast, the panel concluded that there was no reason to assume that free L-SeMet would result in an essentially different deposition pattern [49]. However, as SeMet is incorporated randomly into proteins as a substitute for the sulphur analogue Met [25, 37, 50], the degree of expression of particular proteins depends on the yeast strain and the fermentation process [17] as clearly evidenced in Table 1.

The abundance changes reported are irrespective of Se modification and represent the overall abundance of that protein in each of the products compared to SELM-1. The proteins presented in Table 1 are a subset of the overall quantitative results which have been selected based on the fact that selenium modifications were also detected in these proteins. For example, the relative levels of alcohol dehydrogenase (Adh1) are measured based on all identified peptides (modified and unmodified). SeMet containing peptides were detected in Adh1 from products 2, 3 and SELM-1, but the overall abundance of the Adh1 protein was significantly higher in product 3 compared to SELM-1. Proteins with Se modifications including Ahp1, Bmh1, Eno1, Eno2, Sip18 and Mmf1 were also identified in previous studies on Se yeast $[16,25$, $50,51]$ thus corroborating the results presented in Table 1. Three different isoforms of glyceraldehyde-3-phosphate dehydrogenase (Tdh1, Tdh2 and Tdh3) were also identified. GAPDH is ubiquitous in yeast and has previously been reported to incorporate SeMet randomly within the protein [17]. In general, yeast supports a high degree of SeMet incorporation, by replacing about $30 \%$ of all Met with SeMet [24, 25, 50]. 
a
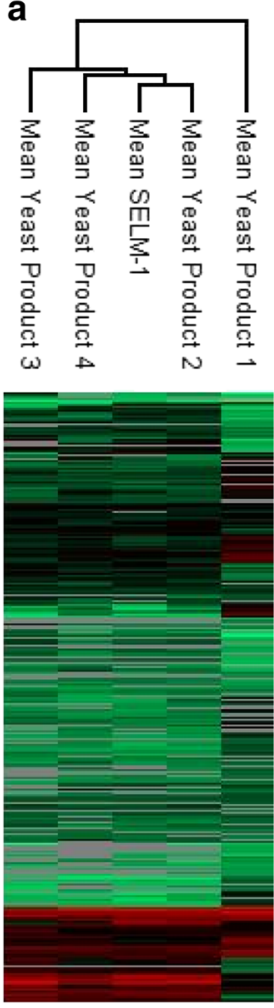

b
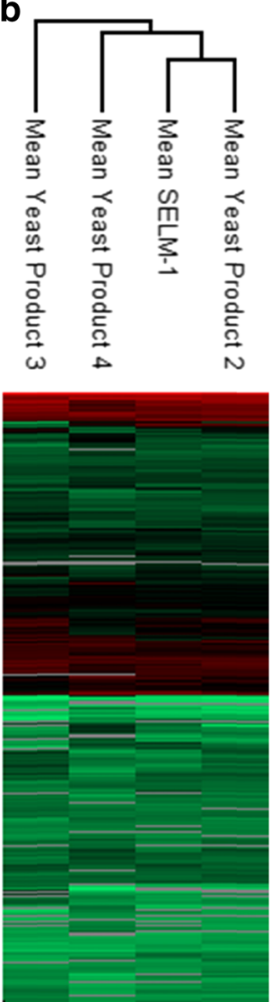

Fig 4 Heat maps demonstrating the hierarchical clustering of a yeast products $1-4$ plus SELM-1 and $\mathbf{b}$ yeast products $2-4$ plus SELM-1 (product 1 excluded), based on relative protein abundances. Lowabundance proteins are depicted in green and high abundant proteins are depicted in red. Grey shading indicates that protein was not identified in the relevant product (colour figure online)

However, within peptides from the same protein, SeMet/Met ratios will vary depending on the differential exposure to oxidative or enzymatic degradation of SeMet side chain and its position in the protein (buried or exposed), and also to the change in the production rate of each protein after Se addition to growth media [50]. Differences in protein content might also be ascribed to diverse manufacturing methods or bioprocessing to which specific yeast is subjected during fermentation, recovery and drying operations [52-54]. For example, Tdh3 was identified in two products but at opposing abundance levels. As glyceraldehyde-3-phosphate dehydrogenase is involved in oxidation-reduction pathways, differential expression may be due to stress imposed by Se salt addition during fermentation, thus highlighting that a range of divergent manufacturing methods may used to generate Seenriched yeast products $[16,39]$ resulting in inherent differences between preparations. It is clear that bioavailability of SeMet will be dependent not only on the abundance of a particular Se-containing protein but also on the position of SeMet residues within the protein; therefore, consideration must be given to the strain-specific deposition of Se into individual protein and peptide-containing fractions [55]. As Se yeast is produced commercially by methods which are proprietary and/or patented $[32,56]$, there is a need for straightforward protocols like the one presented, allowing rapid characterisation and quantitation of Se-enriched yeast samples [57].

Beside SeMet, Se is known to occur in SeCys and is referred to as the 21st amino acid because its specific insertion into Se-proteins is directed by the SeCys insertion sequence (SECIS) element [17]. As the $S$. cerevisiae genome does not contain the SECIS element, SeCys in Se yeast can only be inserted by the competition of Se with sulphur in the Cys synthesis pathway, leading to the non-specific SeCys incorporation. SeCys was not formally identified in the selenoproteome of Se yeast until recently, when Bierla et al. demonstrated the considerable incorporation of SeCys in proteins of the yeast proteome despite the absence of the UGA codon [50]. Therefore, the identification of 14 SeCys modifications among four products in the present study significantly adds to recent discoveries. In essence, this proteome level characterisation of yeast products provides a unique fingerprint of product origin and reproducibility, which is essential for regulatory and safety agencies to approve Se-enriched yeast products for animal nutrition [17]. Further bioinformatic interrogation of the data using Gene Ontology analysis identified a number of biological processes that showed variation between each of the products compared to SELM-1.

\section{Proteomic Comparison of Yeast Products to SELM-1 Using} Gene Ontology Analysis

Proteomic analysis revealed 374 individual proteins that showed some change in abundance in either yeast product 2 , 3 or 4 in comparison to the reference material SELM-1 (qualitative and quantitative results). In concordance with the previously reported hierarchical clustering heat maps, product 2 demonstrated the least variation from SELM-1, with 26 proteins showing decreased abundance and 27 proteins increasing in abundance compared to SELM-1, whereas product 3 demonstrated the most variation from SELM-1, with 112 proteins showing decreased abundance and 171 increasing in abundance. Bioinformatic interrogation of the data using Gene Ontology analysis revealed a number of biological processes that showed variation between each of the products compared to SELM-1. A number of biological processes were altered/affected in the individual products (when compared to SELM-1), including translation, transcription, transport and oxidation-reduction processes. The net number of proteins that were higher or lower in abundance in each product, categorised by biological process and relative to SELM-1, is shown in Fig. 5.

It is well recognised that Se plays a key role in several biological processes, including the response to oxidative stress, DNA damage and repair $[4,58]$. The results presented in Fig. 5 demonstrate differential protein abundance between 
Table 1 SeMet/SeCys-containing proteins with quantitative/qualitative changes in abundance relative to SELM-1

\begin{tabular}{|c|c|c|c|c|c|c|c|c|}
\hline $\begin{array}{l}\text { Fold Change } \\
\text { Yeast Product } \\
2 \text { v SELM-1 }\end{array}$ & $\begin{array}{l}\text { Fold Change } \\
\text { Yeast Product } \\
\text { 3 v SELM-1 }\end{array}$ & $\begin{array}{c}\text { Fold Change } \\
\text { Yeast Product } \\
4 \text { v SELM-1 }\end{array}$ & Gene Name & Protein IDs & Peptides & $\begin{array}{c}\text { Sequence } \\
\text { coverage } \\
{[\%]}\end{array}$ & $\begin{array}{c}\text { Mol. weight } \\
\text { [kDa] }\end{array}$ & Protein Description \\
\hline & -2.6954 & & $\overline{A D H 1}$ & YOL086C & 20 & 61.8 & 36.849 & Alcohol dehydrogenase \\
\hline & & 4.8329 & $A D H 2$ & YMR303C & 14 & 37.1 & 36.731 & Glucose-repressible alcohol dehydrogenase II \\
\hline \multirow[t]{11}{*}{-2.9690} & -3.7902 & -2.4416 & $A H P I$ & YLR109W & 12 & 89.2 & 19.114 & Thiol-specific peroxiredoxin \\
\hline & 2.0078 & & $A L D 4$ & YOR374W & 22 & 58.6 & 56.723 & Mitochondrial aldehyde dehydrogenase \\
\hline & Unique to SELM-1 & & $B M H 1$ & YER177W & 14 & 50.6 & 30.091 & 14-3-3 protein, major isoform \\
\hline & -3.7915 & & $C M D 1$ & YBR109C & 13 & 97.3 & 16.135 & Calmodulin \\
\hline & & -2.1744 & COX4 & YGL187C & 13 & 79.4 & 17.142 & Subunit IV of cytochrome c oxidase \\
\hline & & -5.3034 & $C Y C l$ & YJR048W & 12 & 67 & 12.182 & Cytochrome c, isoform 1 \\
\hline & & -4.4841 & DDR48 & YMR173W & 16 & 65.3 & 46.233 & DNA damage-responsive protein \\
\hline & 2.2927 & & $E G D 2$ & YHR193C & 7 & 47.7 & 18.709 & $\begin{array}{l}\text { Alpha subunit of the heteromeric nascent } \\
\text { polypeptide-associated complex (NAC) }\end{array}$ \\
\hline & -2.1225 & & ENOI & YGR254W & 31 & 81.2 & 46.816 & Enolase I \\
\hline & -2.1858 & & ENO2 & YHR174W & 33 & 84.7 & 46.914 & Enolase II \\
\hline & & -5.4184 & GAS5 & YOL030W & 9 & 25 & 51.869 & 1,3-beta-glucanosyltransferase \\
\hline \multirow[t]{8}{*}{-2.0275} & & & GIS2 & YNL255C & 8 & 60.1 & 17.103 & Translational activator for mRNAs \\
\hline & & 2.7239 & GND1 & YHR183W & 15 & 39.9 & 53.543 & 6-phosphogluconate dehydrogenase \\
\hline & -43.6679 & -3.4679 & $H M F 1$ & YER057C & 9 & 96.9 & 13.906 & $\begin{array}{l}\text { Member of the p14.5 protein family with } \\
\text { similarity to Mmf1p }\end{array}$ \\
\hline & -3.8409 & & HNTI & YDL125C & 4 & 27.2 & 17.679 & Adenosine 5'-monophosphoramidase \\
\hline & 2.6416 & & $H S P 10$ & YOR020C & 7 & 71.7 & 11.372 & $\begin{array}{l}\text { Mitochondrial matrix co-chaperonin that } \\
\text { inhibits the ATPase activity of } \mathrm{Hsp} 60 \mathrm{p}\end{array}$ \\
\hline & & $\begin{array}{l}\text { Unique to } \\
\text { Product } 4\end{array}$ & HSP82 & YPL240C & 26 & 37 & 81.405 & $\begin{array}{l}\text { Hsp90 chaperone required for pheromone } \\
\text { signaling and negative regulation of } \mathrm{Hsflp}\end{array}$ \\
\hline & & -3.0302 & HYP2 & YEL034W & 10 & 75.2 & 17.114 & Translation elongation factor eIF-5A \\
\hline & 3.9702 & & IGDI & YFR017C & 10 & 64.6 & 21.783 & Cytoplasmic protein that inhibits Gdb1p \\
\hline \multirow[t]{10}{*}{-3.5665} & -6.7146 & & LEU2 & YCL018W & 25 & 77.5 & 38.952 & Beta-isopropylmalate dehydrogenase (IMDH) \\
\hline & -3.2827 & & MET6 & YER091C & 42 & 59.5 & 85.859 & Cobalamin-independent methionine synthase \\
\hline & & -2.6696 & $M L C 1$ & YGL106W & 16 & 81.9 & 16.444 & $\begin{array}{l}\text { Essential light chain for Myo1p, light chain } \\
\text { for Myo2p }\end{array}$ \\
\hline & -28.6555 & -19.3447 & $M M F 1$ & YIL051C & 6 & 58.6 & 15.908 & Mitochondrial protein \\
\hline & & 2.6396 & $M S C l$ & YML128C & 16 & 35.9 & 59.588 & Protein of unknown function \\
\hline & 2.3653 & & NHP6A & YPR052C & 8 & 63.4 & 10.802 & High-mobility group (HMG) protein \\
\hline & 2.0664 & & NHP6B & YBR089C-A & 7 & 53.5 & 11.476 & High-mobility group (HMG) protein \\
\hline & -3.2049 & -2.1213 & OYE2 & YHR179W & 7 & 20 & 45.01 & $\begin{array}{l}\text { Conserved NADPH oxidoreductase } \\
\text { containing flavin mononucleotide (FMN) }\end{array}$ \\
\hline & 5.8820 & -3.6778 & PCK1 & YKR097W & 12 & 23 & 60.983 & Phosphoenolpyruvate carboxykinase \\
\hline & -2.4620 & 2.6759 & PET10 & YKR046C & 17 & 59.7 & 31.246 & $\begin{array}{l}\text { Protein of unknown function that co-purifies } \\
\text { with lipid particles }\end{array}$ \\
\hline-2.0013 & -2.7838 & & $P G M 2$ & YMR105C & 28 & 61.5 & 63.088 & Phosphoglucomutase \\
\hline \multirow[t]{2}{*}{-3.5104} & -3.2205 & & $P N C l$ & YGL037C & 4 & 28.7 & 24.993 & Nicotinamidase \\
\hline & 4.4443 & & PRB1 & YEL060C & 13 & 21.1 & 69.621 & Vacuolar proteinase B (yscB) \\
\hline
\end{tabular}

Fold changes are based on protein intensities as calculated using MaxQuant LFQ algorithm and only proteins with a significant change in abundance $(P<$ 0.05 ; $\geq 2$-fold change in abundance) are included. Positive numbers indicate increased abundance and negative figures indicated decreased abundance, relative to the levels in SELM-1. Qualitative differences are also included and indicated as unique to a specific product. Values in red represent proteins with a higher abundance in products 2, 3 or 4 relative to SELM-1, and green indicates a lower abundance of that protein relative to SELM-1 (quantitative or qualitative) (colour table online) 
Table 1 (continued)

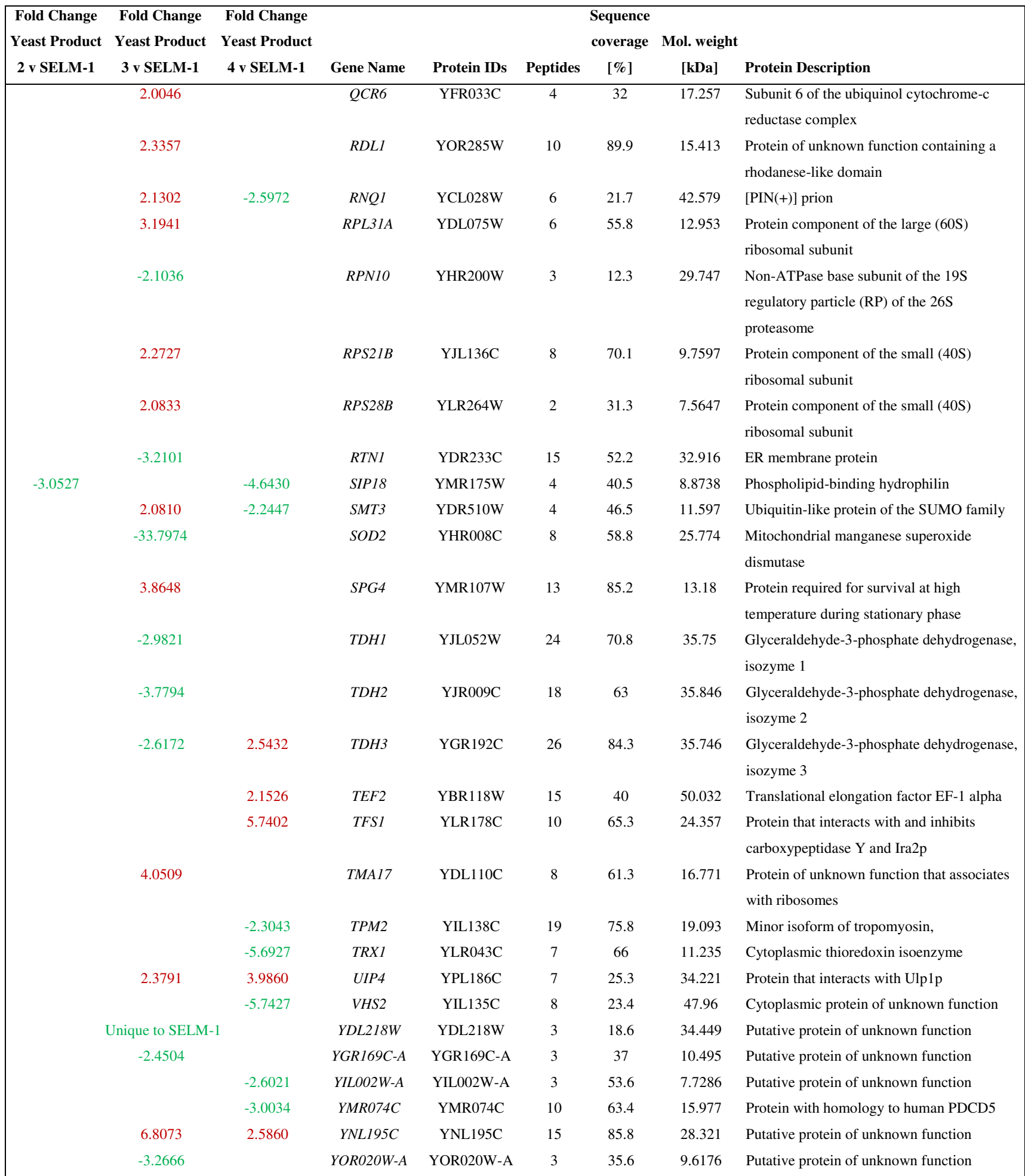

Se-enriched yeast products in a number of biological processes. Thus, the routes by which each of the individual product compounds are metabolised and the relative abundance of their metabolites will be entwined with the efficacy of $\mathrm{Se}$ compounds in disease prevention and treatment [31]. It is also worth noting that the water extraction used in this study is vastly different from volatile conditions encountered in the GI tract where conditions will solubilise some proteins and 
Fig. 5 Proteins with differential abundances among yeast products 2, 3 and 4 compared to SELM-1, mapped to biological process (GO annotation using FungiFun application). Number of proteins with higher or lower abundance, relative to SELM-1, are displayed above and below the $x$-axis, respectively

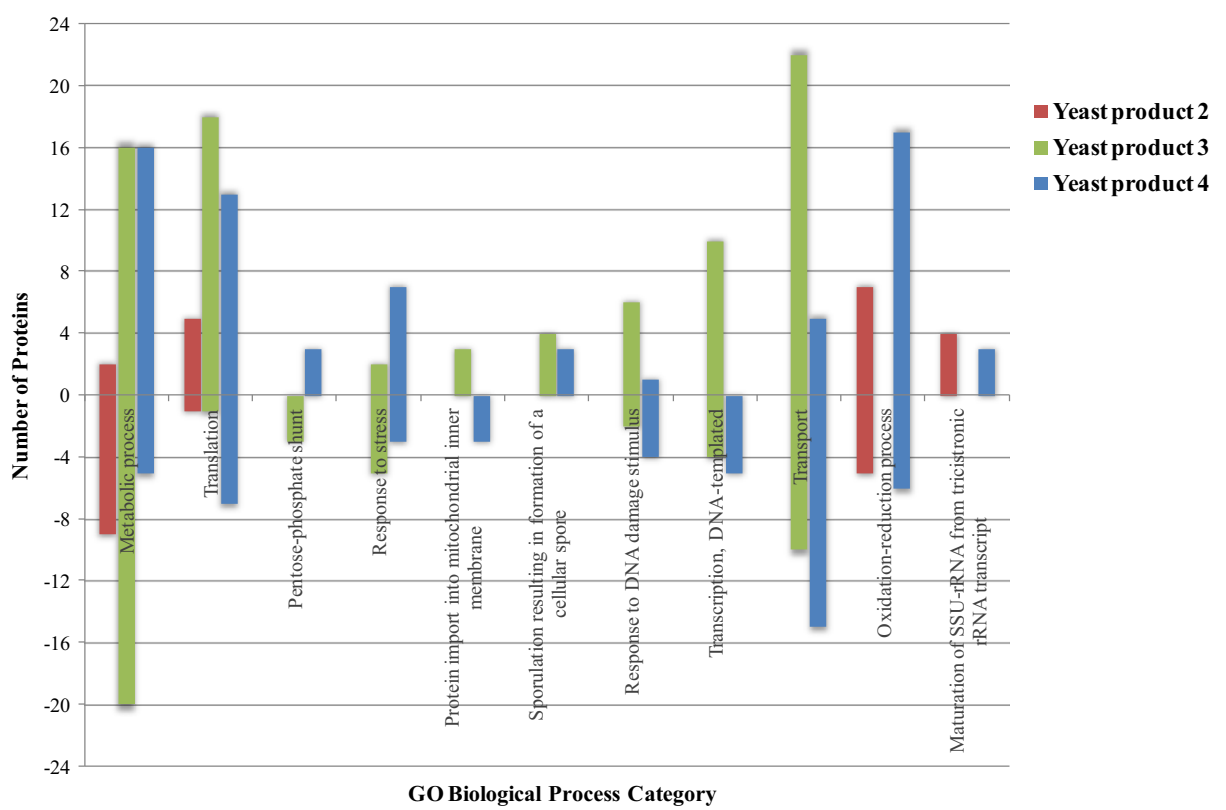

destabilise others [59]. Therefore, the extent to which the active forms of yeast proteins identified can be transported intact across the intestinal barrier, and the biological effect of such proteins or corresponding peptides must be determined in preclinical animal models before any definitive conclusions can be made on potential beneficial health effects [16]. Nevertheless, knowledge of a group of proteins that respond to $\mathrm{Se}$ supplementation will be useful in the assessment of a particular metabolic status [60].

\section{KEGG Metabolic Pathway Analysis}

Using KEGG pathway analysis [61] and FungiFun analysis [62], the enzymes with altered abundances relative to SELM1 were mapped on the glutathione metabolism and Cys/Met metabolism pathways (Fig. 6). These pathways were previously observed to be altered in response to Se, and Se-containing proteins that underwent a significant change in abundance have been identified (data not shown). Proteins involved in Cys/Met metabolism were mapped to show the effect of product difference on proteins from this pathway (Fig. 6a). For example, the protein encoded by SPE3 (spermidine synthase), which utilises $S$-adenosylmethioninamine for the production of spermidine, demonstrated increased abundance in product 4 only, once again demonstrating differences between the products. This may signify an increase in the production of spermidine, which is associated with increased cell lifespan and suppression of oxidative stress in yeast [63].

One protein, Sam2, which is involved in Met conversion to $S$-adenosyl methionine (SAM) was observed at a significantly higher level in products 3 and 4 compared to SELM-1 (Fig. 6a). SAM, also known as AdoMet, is an essential molecule that exists in all living organisms and is also a precursor molecule in the aminopropylation and transulfuration pathways [64]. It is distributed to virtually all body tissues and fluids and is of fundamental importance in a number of biochemical reactions involving enzymatic transmethylation, contributing to the synthesis, activation and/or metabolism of such compounds as hormones, neurotransmitters, nucleic acids, proteins and phospholipids $[20,65,66]$. SAM is effective in the treatment of clinical disorders such as liver disease, osteoarthritis and depression and has been used extensively as an approved prescription medicinal dietary supplement in Europe. Chu et al. [67] recently reported the urgent need to enhance the production of SAM to meet growing demand. Notably, S. cerevisiae has two distinct SAM-synthetase genes, named $S A M 1$ and $S A M 2$, which arose from gene duplication [68] and share a high degree of similarity [69]. Although SAM1 and SAM2 encode functionally equivalent SAM synthetases, they are regulated differently [70]. Both genes undergo feedback repression by SAM, like other genes of sulphur aminoacid metabolism, but expression of SAM2 also increases during growth, which overrides the SAM-mediated repression [64, 70]. Thomas et al. [69] also reported that $S A M 1$ and $S A M 2$ are regulated transcriptionally by excess methionine in the growth medium, but in an opposing manner. Expression of the SAM2 gene is induced by the presence of methionine in the growth medium, whereas $S A M 1$ is repressed [69].

Interestingly, $S$-adenosylhomocysteine hydrolase (Sah1) and methionine synthase (Met6) are also involved in the SAM cycle, also known as the activated methyl cycle. Within this cycle, upon donating the methyl group, SAM is converted to $S$-adenosylhomocysteine (AdoHcy) which is then 
hydrolyzed to homocysteine by Sah1 [71]. Inhibition of Sah1 normally results in an accumulation of cellular AdoHcy, which is often accompanied by a simultaneous rise in SAM because of the feedback inhibition by AdoHcy on most methylation reactions [72]. Therefore, as can be appreciated in Fig. 6a, the production of SAM is clearly influenced by choice of production strain and/or manipulation of culture conditions.

Similarly, a number of proteins associated with glutathione metabolism were detected (Fig. 6b). Proteins encoded by OXP1, DUG1, GND1, GTT1, SPE3, RNR2 and RNR4 were annotated to the glutathione metabolism KEGG pathway, which was significantly represented in the data $(P=$ 0.00008; FungiFun analysis, data not shown). The chemical and physical resemblance between $\mathrm{Se}$ and $\mathrm{S}$ establishes that both these elements share common metabolic pathways [73]. In addition to being a constituent of cysteine and methionine, sulphur (S) is also present in glutathione, an essential metabolite in almost all eukaryotic organisms playing a key role in redox homeostasis and in the cellular response to oxidative stress [74]. Expression of glutathione $S$-transferase (Gtt1) is reportedly induced after diauxic shift and remains high throughout the stationary phase [75], while phosphogluconate dehydrogenase (Gnd1) is important for protecting yeast from oxidative stress [76]. Glutathione utilisation in S. cerevisiae has also been shown to be dependent on the presence of a glutathione transporter and an alternative pathway of
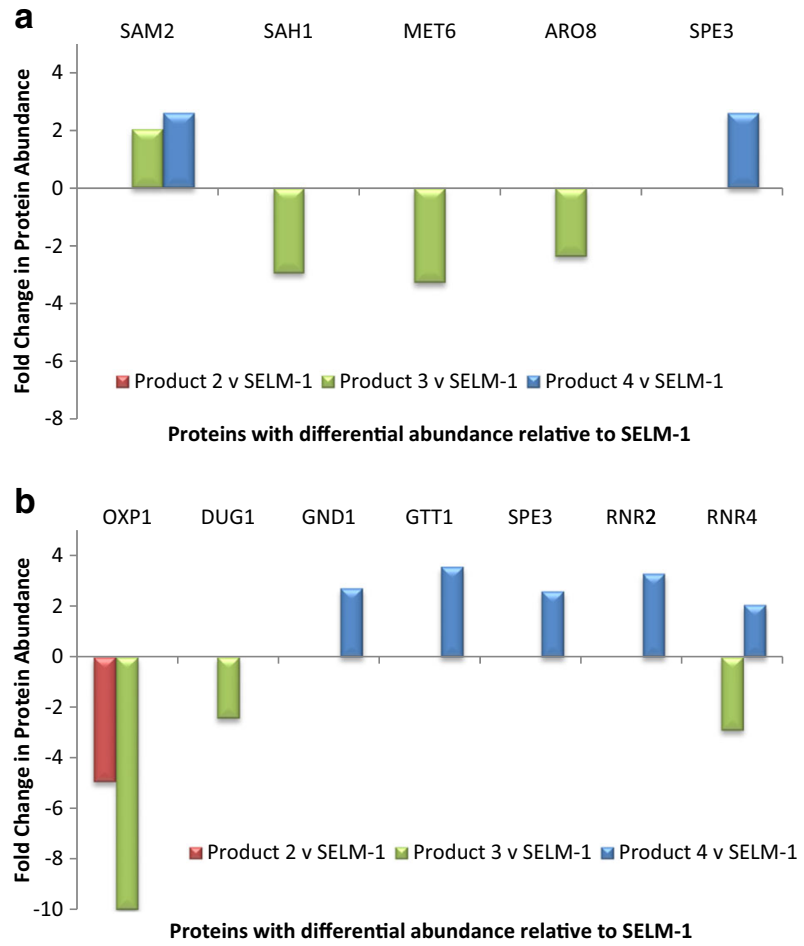

Fig. 6 a Cysteine/methionine-metabolism and b glutathione-metabolism related proteins with differential abundance relative to SELM-1. Gene names are indicated above the $x$-axis and fold difference of individual proteins is on the $y$-axis glutathione degradation that involves the 'Dug pathway complex' comprising Dug1 [74]. The remaining annotated proteins have peripheral roles in glutathione metabolism. For example, Oxp1 is a 5-oxoprolinase which functions to produce glutamate and normally forms part of the gamma-glutamyl cycle [77].

As $S$. cerevisiae is unable to distinguish between $\mathrm{Se}$ and $\mathrm{S}$ [73], it is unsurprising that Se supplementation affected the levels of these glutathione metabolism-related proteins in Se yeast products. Both Gtt1 and Gnd1 were observed to increase in abundance following Se enrichment and were present at significantly higher levels in product 4 compared to SELM1. An additional glutathione transferase, $\mathrm{Ecm} 4$, was also uniquely identified in product 4 . Other glutathione metabolism-related proteins were detected at significantly lower levels in either product 3 or product 2 relative to SELM-1. It is worth noting that SAM is also the principal biological methyl donor and a precursor for glutathione [78]. Once again, product 2 is identified to be the most dissimilar to all other products analysed; however, all products demonstrated differential protein abundance relative to SELM-1. Altogether, these results point to the pathways and systems that are affected following Se enrichment yet differ considerably among the Se-enriched yeast products examined.

\section{Conclusion}

To date, speciation data have made it possible to discriminate between yeast containing organic Se and yeast mixed with inorganic selenate or selenite, to distinguish Se-rich yeasts produced by different manufacturers and to verify batch-to-batch reproducibility. Recent advances in mass spectrometry and quantitative proteomics enable analysis of proteins in a much more comprehensive and highthroughput manner than previously possible. In addition, the availability of SELM-1 reference material has improved the quality assurance of the analyses of Seenriched yeast. In this study, we have demonstrated that commercial Se-enriched yeast products differ significantly in terms of protein abundance and associated metabolic pathways in addition to SeMet content. In essence, all of the presented data confirm that Se yeast products are distinct from each other. This distinctness is due to the differential deposition of Se present within individual yeast fractions indicating that retention and thus bioavailability of Se from each of these products are different. Investigating the bioavailability of Se yeast products using in vitro digestion will further differentiate the products in terms of bio efficacy.

Acknowledgments LC-MS facilities were funded by a competitive award from Science Foundation Ireland (12/RI/2346 (3)) to SD. 
Conflict of Interest SF, RM, CC and PW are employees of Alltech who retail selenium-enriched yeast as a commercial feed additive.

\section{References}

1. Zhang L, Hu B, Li W, Che R, Deng K, Li H, Yu F, Ling H, Li Y, Chu C (2013) OsPT2, a phosphate transporter, is involved in the active uptake of selenite in rice. New Phytol 201(4):1183-1191

2. Bierla K, Vacchina V, Szpunar J, Bertin G, Lobinski R (2008) Simultaneous derivatization of selenocysteine and selenomethionine in animal blood prior to their specific determination by $2 \mathrm{D}$ sizeexclusion ion-pairing reversed-phase HPLC-ICP MS. J Anal At Spectrom 23(4):508-513

3. Wang W, Chen Z, Davey D, Naidu R (2009) Extraction of selenium species in pharmaceutical tablets using enzymatic and chemical methods. Microchim Acta 165(1):167-172

4. Barger J, Kayo T, Pugh T, Vann J, Power R, Dawson K, Weindruch R, Prolla T (2011) Gene expression profiling reveals differential effects of sodium selenite, selenomethionine, and yeast-derived seleni$\mathrm{um}$ in the mouse. Genes Nutr 7(2):155-165

5. Zeng H, Jackson M, Cheng W-H, Combs G Jr (2011) Chemical form of selenium affects its uptake, transport, and glutathione peroxidase activity in the human intestinal Caco-2 cell model. Biol Trace Elem Res 143(2):1209-1218

6. Alzate A, Pérez-Conde MC, Gutiérrez AM, Cámara C (2010) Selenium-enriched fermented milk: a suitable dairy product to improve selenium intake in humans. Int Dairy J 20(11):761-769

7. Briens M, Mercier Y, Rouffineau F, Vacchina V, Geraert P-A (2013) Comparative study of a new organic selenium source v. seleno-yeast and mineral selenium sources on muscle selenium enrichment and selenium digestibility in broiler chickens. Br J Nutr 110(04):617-624

8. Xia Y, Hill KE, Byrne DW, Xu J, Burk RF (2005) Effectiveness of selenium supplements in a low-selenium area of China. Am J Clin Nutr 81(4):829-834

9. EFSA (2008) Selenium-enriched yeast as source for selenium added for nutritional purposes in foods for particular nutritional uses and foods (including food supplements) for the general population - scientific opinion of the panel on food additives, flavourings, processing aids and materials in contact with food. EFSA J 766:1-42

10. Murphy R (2013) Understanding different types of organic selenium. Feedstuffs 85(52):31-33

11. Hinojosa-Reyes L, Ruiz-Encinar J, Marchante-Gayun JM, GarciaAlonso JI, Sanz-Medel A (2006) Selenium bioaccessibility assessment in selenized yeast after "in vitro" gastrointestinal digestion using two-dimensional chromatography and mass spectrometry. J Chromatogr A 1110(1-2):108-116

12. Encinar JR, Sliwka-Kaszynska M, Polatajko A, Vacchina V, Szpunar J (2003) Methodological advances for selenium speciation analysis in yeast. Anal Chim Acta 500(1-2):171-183

13. B'Hymer C, Caruso JA (2000) Evaluation of yeast-based selenium food supplements using high-performance liquid chromatography and inductively coupled plasma mass spectrometry. J Anal At Spectrom 15(12):1531-1539

14. Heras I, Palomo M, Madrid Y (2011) Selenoproteins: the key factor in selenium essentiality. State of the art analytical techniques for selenoprotein studies. Anal Bioanal Chem 400(6):1717-1727

15. Ganesh V, Hettiarachchy NS (2012) Nutriproteomics: a promising tool to link diet and diseases in nutritional research. Biochim Biophys Acta (BBA) - Proteins Proteomics 1824(10):1107-1117

16. El-Bayoumy K, Das A, Russell S, Wolfe S, Jordan R, Renganathan K, Loughran TP, Somiari R (2012) The effect of selenium enrichment on baker's yeast proteome. J Proteome 75(3):1018-1030
17. Bierla K, Szpunar J, Yiannikouris A, Lobinski R (2012) Comprehensive speciation of selenium in selenium-rich yeast. TrAC Trends Anal Chem 41:122-132

18. Mester Z, Willie S, Yang L, Sturgeon R, Caruso J, Fernández M, Fodor P, Goldschmidt R, Goenaga-Infante H, Lobinski R, Maxwell P, McSheehy S, Polatajko A, Sadi B, Sanz-Medel A, Scriver C, Szpunar J, Wahlen R, Wolf W (2006) Certification of a new selenized yeast reference material (SELM-1) for methionine, selenomethinone and total selenium content and its use in an intercomparison exercise for quantifying these analytes. Anal Bioanal Chem 385(1):168-180

19. Ward P, Connolly C, Murphy R (2012) Accelerated determination of selenomethionine in selenized yeast: validation of analytical method. Biol Trace Elem Res 151(3):446-450

20. Dolan SK, Owens RA, O'Keeffe G, Hammel S, Fitzpatrick DA, Jones Gary W, Doyle S (2014) Regulation of nonribosomal peptide synthesis: bis-thiomethylation attenuates gliotoxin biosynthesis in Aspergillus fumigatus. Chem Biol 21(8):999-1012

21. Cox J, Mann M (2008) MaxQuant enables high peptide identification rates, individualized p.p.b.-range mass accuracies and proteome-wide protein quantification. Nat Biotechnol 26(12):1367-1372

22. Perucchietti P, Litjens W (2012) Why check selenomethionine levels in selenium yeast? Allaboutfeednet 20(6):12-13

23. Polatajko A, Sliwka-Kaszynska M, Dernovics M, Ruzik R, Ruiz Encinar J, Szpunar J (2004) A systematic approach to selenium speciation in selenized yeast. J Anal At Spectrom 19(1):114-120

24. Goenaga Infante H, Hearn R, Catterick T (2005) Current mass spectrometry strategies for selenium speciation in dietary sources of highselenium. Anal Bioanal Chem 382(4):957-967

25. McSheehy S, Kelly J, Tessier L, Mester Z (2005) Identification of selenomethionine in selenized yeast using two-dimensional liquid chromatography-mass spectrometry based proteomic analysis. Analyst 130(1):35-37

26. EFSA (2006) Opinion of the scientific panel on additives and products or substances used in animal feed on the safety and efficacy of the product Sel-Plex ${ }^{\circledR} 2000$ as a feed additive according to Regulation (EC) No 1831/2003. EFSA J 348:1-40

27. EFSA (2006) Opinion of the Panel on additives and products or substances used in animal feed (FEEDAP) on the safety and efficacy of the product Selenium enriched yeast (Saccharomyces cerevisiae NCYC R397) as a feed additive for all species in accordance with Regulation (EC) No 1831/2003. EFSA J :1-23

28. EFSA (2009) Scientific Opinion of the Panel on Additives and Products or Substances used in Animal Feed (FEEDAP) on a request from the European Commission on the Safety and efficacy of SELS $\mathrm{AF}$ (Selenium enriched yeast from Saccharomyces cerevisiae CNCM I-3399) as feed additive for all species. EFSA J 992:1-24

29. Schrauzer GN (2003) The nutritional significance, metabolism and toxicology of selenomethionine. Adv Food Nutr Res 47:73-112

30. Rao Y, McCooeye M, Windust A, Bramanti E, D’Ulivo A, Mester Z (2010) Mapping of selenium metabolic pathway in yeast by liquid chromatography-orbitrap mass spectrometry. Anal Chem 82(19): $8121-8130$

31. Weekley CM, Harris HH (2013) Which form is that? The importance of selenium speciation and metabolism in the prevention and treatment of disease. Chem Soc Rev 42(23):8870-8894

32. Suhajda A, Hegoczki J, Janzso B, Pais I, Vereczkey G (2000) Preparation of selenium yeasts I. Preparation of selenium-enriched Saccharomyces cerevisiae. J Trace Elem Med Biol 14(1):43-47

33. Suzuki KT (2005) Metabolomics of selenium: Se metabolites based on speciation studies. J Health Sci 51(2):107-114

34. Hinojosa-Reyes L, Marchante-Gayon JM, Garcia Alonso JI, SanzMedel A (2006) Application of isotope dilution analysis for the evaluation of extraction conditions in the determination of total selenium and selenomethionine in yeast-based nutritional supplements. J Agric Food Chem 54(5):1557-1563 
35. Moreda-Piñeiro J, Moreda-Piñeiro A, Romarís-Hortas V, MoscosoPérez C, López-Mahía P, Muniategui-Lorenzo S, Bermejo-Barrera P, Prada-Rodríguez D (2011) In-vivo and in-vitro testing to assess the bioaccessibility and the bioavailability of arsenic, selenium and mercury species in food samples. TrAC Trends Anal Chem 30(2):324 345

36. Rayman MP (2008) Food-chain selenium and human health: emphasis on intake. Br J Nutr 100(2):254-268

37. B'Hymer C, Caruso JA (2006) Selenium speciation analysis using inductively coupled plasma-mass spectrometry. J Chromatogr A 1114(1):1-20

38. Cabanero AI, Madrid Y, Camara C (2004) Selenium and mercury bioaccessibility in fish samples: an in vitro digestion method. Anal Chim Acta 526(1):51-61

39. Rayman MP (2004) The use of high-selenium yeast to raise selenium status: how does it measure up? Br J Nutr 92(04):557-573

40. Połatajko A, Banaś B, Encinar JR, Szpunar J (2005) Investigation of the recovery of selenomethionine from selenized yeast by twodimensional LC-ICP MS. Anal Bioanal Chem 381(4):844-849

41. Gammelgaard B, Cornett C, Olsen Jr, Bendahl L, Hansen SH (2003) Combination of LC-ICP-MS, LC-MS and NMR for investigation of the oxidative degradation of selenomethionine. Talanta 59(6):11651171

42. Zembrzuska J, Matusiewicz H, Polkowska-Motrenko H, Chajduk E (2014) Simultaneous quantitation and identification of organic and inorganic selenium in diet supplements by liquid chromatography with tandem mass spectrometry. Food Chem 142:178-187

43. Tastet L, Schaumlöffel D, Bouyssiere B, Lobinski R (2006) Capillary HPLC-ICP MS mapping of selenocompounds in spots obtained from the 2-D gel electrophoresis of the water-soluble protein fraction of selenized yeast. Anal Bioanal Chem 385(5):948-953

44. Nesvizhskii AI, Vitek O, Aebersold R (2007) Analysis and validation of proteomic data generated by tandem mass spectrometry. Nat Methods 4(10):787-797

45. Baudouin-Cornu P, Lagniel G, Chédin S, Labarre J (2009) Development of a new method for absolute protein quantification on 2-D gels. Proteomics 9(20):4606-4615

46. McJury Richardson B, Soderblom EJ, Moseley MA (2013) Automated, reproducible, titania-based phosphopeptide enrichment strategy for label-free quantitative phosphoproteomics. J Biomol Tech 24(1):8-16

47. Asuero AG, Sayago A, Gonzalez AG (2006) The correlation coefficient: an overview. Crit Rev Anal Chem 36:41-59

48. Clough T, Key M, Ott I, Ragg S, Schadow G, Vitek O (2009) Protein quantification in label-free LC-MS experiments. J Proteome Res $8(11): 5275-5284$

49. EFSA (2013) Scientific opinion on the safety and efficacy of Lselenomethionine as feed additive for all animal species. EFSA J 11(5):3219

50. Bierla K, Bianga J, Ouerdane L, Szpunar J, Yiannikouris A, Lobinski $\mathrm{R}$ (2013) A comparative study of the Se/S substitution in methionine and cysteine in Se-enriched yeast using an inductively coupled plasma mass spectrometry (ICP MS)-assisted proteomics approach. J Proteome 87:26-39

51. Tastet L, Schaumloffel D, Lobinski R (2008) ICP-MS-assisted proteomics approach to the identification of selenium-containing proteins in selenium-rich yeast. J Anal At Spectrom 23(3):309-317

52. Goyco JA, Asenjo CF (1947) The net protein value of food yeast. J Nutr 33:593

53. Kieliszek M, Blazejak S (2013) Selenium: significance, and outlook for supplementation. Nutrition 29(5):713-718

54. Mapelli V, Hillestrom PR, Kapolna E, Larsen EH, Olsson L (2011) Metabolic and bioprocess engineering for production of selenized yeast with increased content of seleno-methylselenocysteine. Metab Eng 13(3):282-293
55. Rayman MP, Goenaga Infante H, Sargent M (2008) Food-chain selenium and human health: spotlight on speciation. Br J Nutr 100(2): 238-253

56. Schrauzer GN (2006) Selenium yeast: composition, quality, analysis, and safety. Pure Appl Chem 78(1):105-109

57. Far J, Preud'homme H, Lobinski R (2010) Detection and identification of hydrophilic selenium compounds in selenium-rich yeast by size exclusion-microbore normal-phase HPLC with the on-line ICPMS and electrospray Q-TOF-MS detection. Anal Chim Acta 657(2): 175-190

58. Clark LC, Combs GF Jr, Turnbull BW, Slate EH, Chalker DK, Chow J, Davis LS, Glover RA, Graham GF, Gross EG, Krongrad A, Lesher JL Jr, Kim Park H, Sanders BB Jr, Smith CL, Taylor JR (1996) Effects of selenium supplementation for cancer prevention in patients with carcinoma of the skin: a randomized controlled trial. JAMA 276(24): 1957-1963

59. von der Haar T (2007) Optimized protein extraction for quantitative proteomics of yeasts. PLoS ONE 2(10):e1078

60. Mahn AV, Munoz MC, Zamorano MJ (2009) Discovery of biomarkers that reflect the intake of sodium selenate by nutritional proteomics. J Chromatogr Sci 47(9):840-843

61. Kanehisa M, Goto S (2000) KEGG: Kyoto Encyclopedia of Genes and Genomes. Nucleic Acids Res 28(1):27-30

62. Priebe S, Linde J, Albrecht D, Guthke R, Brakhage AA (2011) FungiFun: a web-based application for functional categorization of fungal genes and proteins. Fungal Genet Biol 48(4):353-358

63. Eisenberg T, Knauer H, Schauer A, Buttner S, Ruckenstuhl C, Carmona-Gutierrez D, Ring J, Schroeder S, Magnes C, Antonacci L, Fussi H, Deszcz L, Hartl R, Schraml E, Criollo A, Megalou E, Weiskopf D, Laun P, Heeren G, Breitenbach M, GrubeckLoebenstein B, Herker E, Fahrenkrog B, Frohlich K-U, Sinner F, Tavernarakis N, Minois N, Kroemer G, Madeo F (2009) Induction of autophagy by spermidine promotes longevity. Nat Cell Biol 11(11):1305-1314

64. Dato L, Berterame N, Ricci M, Paganoni P, Palmieri L, Porro D, Branduardi P (2014) Changes in SAM2 expression affect lactic acid tolerance and lactic acid production in Saccharomyces cerevisiae. Microb Cell Factories 13:147

65. Malkowski MG, Quartley E, Friedman AE, Babulski J, Kon Y, Wolfley J, Said M, Luft JR, Phizicky EM, DeTitta GT, Grayhack EJ (2007) Blocking S-adenosylmethionine synthesis in yeast allows selenomethionine incorporation and multiwavelength anomalous dispersion phasing. Proc Natl Acad Sci 104(16):6678-6683

66. Luo J, Li Y-N, Wang F, Zhang W-M, Geng X (2010) SAdenosylmethionine inhibits the growth of cancer cells by reversing the hypomethylation status of c-myc and $\mathrm{H}$-ras in human gastric cancer and colon cancer. Int J Biol Sci 6(7):784-795

67. Chu J, Qian J, Zhuang Y, Zhang S, Li Y (2013) Progress in the research of S-adenosyl-1-methionine production. Appl Microbiol Biotechnol 97(1):41-49

68. Cherest H, Surdin-Kerjan Y, Exinger F, Lacroute F (1978) SAdenosyl methionine requiring mutants in Saccharomyces cerevisiae: evidences for the existence of two methionine adenosyl transferases. Mol Gen Genet 163(2):153-167

69. Thomas D, Rothstein R, Rosenberg N, Surdin-Kerjan Y (1988) SAM2 encodes the second methionine S-adenosyl transferase in Saccharomyces cerevisiae: physiology and regulation of both enzymes. Mol Cell Biol 8(12):5132-5139

70. Thomas D, Surdin-Kerjan Y (1991) The synthesis of the two Sadenosyl-methionine synthetases is differently regulated in Saccharomyces cerevisiae. Mol Gen Genet 226(1-2):224-232

71. Ravanel S, Block MA, Rippert P, Jabrin S, Curien G, Rebeille F, Douce R (2004) Methionine metabolism in plants: chloroplasts are autonomous for de novo methionine synthesis and can import $\mathrm{S}$ - 
adenosylmethionine from the cytosol. J Biol Chem 279(21):2254822557

72. Chiang PK (1998) Biological effects of inhibitors of Sadenosylhomocysteine hydrolase. Pharmacol Ther 77(2):115-134

73. Mapelli V, Hillestrøm PR, Patil K, Larsen EH, Olsson L (2012) The interplay between sulphur and selenium metabolism influences the intracellular redox balance in Saccharomyces cerevisiae. FEMS Yeast Res 12(1):20-32

74. Yadav AK, Desai PR, Rai MN, Kaur R, Ganesan K, Bachhawat AK (2011) Glutathione biosynthesis in the yeast pathogens Candida glabrata and Candida albicans: essential in C. glabrata, and essential for virulence in C. albicans. Microbiology 157(2):484-495

75. Collison EJ, Grant CM (2003) Role of yeast glutaredoxins as glutathione S-transferases. J Biol Chem 278(25):22492-22497
76. Izawa S, Maeda K, Miki T, Mano J, Inoue Y, Kimura A (1998) Importance of glucose-6-phosphate dehydrogenase in the adaptive response to hydrogen peroxide in Saccharomyces cerevisiae. Biochem J 330(Pt 2):811-817

77. Kumar A, Bachhawat AK (2010) OXP1/YKL215c encodes an ATPdependent 5-oxoprolinase in Saccharomyces cerevisiae: functional characterization, domain structure and identification of actin-like ATP-binding motifs in eukaryotic 5-oxoprolinases. FEMS Yeast Res 10(4):394-401

78. Tomasi ML, Ramani K, Lopitz-Otsoa F, Rodríguez MS, Li TWH, Ko K, Yang H, Bardag-Gorce F, Iglesias-Ara A, Feo F, Pascale MR, Mato JM, Lu SC (2010) S-Adenosylmethionine regulates dualspecificity mitogen-activated protein kinase phosphatase expression in mouse and human hepatocytes. Hepatology 51(6):2152-2161 